\title{
Leadership Development: A Hierarchy of Followership Skills During a Crisis
}

\author{
Marilyn Young \\ The University of Texas at Tyler \\ Kerri M. Camp \\ The University of Texas at Tyler \\ Stephen C. Bushardt \\ The University of Texas at Tyler
}

As organizations adapt to significant challenges, such as a pandemic and multiple generations entering the workplace, it is important to have followers who are team players and have skills for the new environment. Understanding and learning followership skills will be necessary for organizational effectiveness. We identified the following three major categories of followership skills and placed them into a hierarchy: Professional, Interpersonal, and Political. Each of these classifications has specific skill sets. A model is also offered as followers progress over time, learning these skills as they become leaders. The progression includes (1) Novice/Apprentice, (2) Team player, (3) Decision Maker, and (4) Leader/Manager.

Keywords: followership, leadership skills, leadership development, changing environments

\section{INTRODUCTION}

Many challenges for leaders currently exist and will continue to increase with our new turbulent environment even after 2020. Two significant challenges in the workplace are the pandemic and managing multiple generations during a crisis. With both the COVID-19 pandemic and different generations in the workplace, effective followership has become increasingly important. A safe workplace with alternative work designs, including telecommuting, will be part of the leader's new environment. Having employees with followership skills seems important as leaders continue to build an effective team. In turn, it will be incumbent on employees to learn new skills as they adapt to new work designs, such as job enlargement. We suggest that understanding followership skills will be vital as leaders adjust to significant changes during the current pandemic. We provide three categories of followership skills and a developmental progression for learning these skills.

\section{BACKGROUND}

Much attention has been given to the Millennial Generation (born 1980-1994) in the workplace regarding their values and using appropriate management techniques. Gen Z (born 1995-2015) will soon 
represent a large percentage of the workforce. One study states that this generation wants guidance and feedback on how to be successful. Moreover, they are talented, eager to learn, and may be invaluable team members and future leaders (McDonald, 2016). Given that Gen Y and Gen Z will be a major force within all professions, this paper examines followership skills, especially for these generations.

Significant research has been conducted on leadership for new employees, especially in the health care professions. While leadership is a needed skill in all professions, the role of followership has received far less attention (Malakyan, 2014). It is paramount for new employees to understand that being a follower is a prerequisite to leadership. However, it is often framed with negative connotations, such as passive, weak, and conforming (Batcheller, 2012), rather than a critical step in future leaders' professional development. For new employees from the Gen Y and Gen Z generations, it is essential to understand that usually one is not placed in a leadership role at the beginning stage of the career. Most of the time, entrylevel employees may not supervise others in their initial position; therefore, followership skills may contribute to the organization while advancing their careers to a future leadership role.

Many educational programs tend to emphasize leadership skills but neglect followership skills. Therefore, new employees often have role ambiguity, resulting in the organization having "too many chefs and not enough cooks." Leaders without effective followers are not very relevant, nor do they have meaningful influence in the organization.

New applicants may often be asked during the interview process: "What skills do you have to contribute to the organization?" They typically respond with "leadership skills," and more than one CEO may respond: "I am the leader, and we do not need another one." As individuals enter the workforce, their contributions to the organization and future career advancement often will depend on their followership skills. For instance, the follower must trust the leader, as he/she is giving up control and thus develops the courage to serve (Batcheller, 2012). We identify these skills in the context of organizational effectiveness and career development for both Gen X and Gen Y employees. The primary aspects of followership involve professionalism, interpersonal skills, and political skills, which are arranged in a hierarchy.

\section{HIERARCHICAL RELATIONSHIP OF FOLLOWERSHIP SKILLS}

Figure 1 shows a hierarchical relationship of followership skills: Professionalism, interpersonal skills, and political skills. Professionalism is a critical and necessary element of followership but is often insufficient in itself. These professional skills provide the foundation on which the other skills are added to facilitate successful followership. Next, interpersonal and political skills are vital to enhancing followership once they master professional skills. Without this foundation, interpersonal skills and political skills provide only a shallow understanding of followership and could likely be counterproductive

\section{Professional Skills}

Organizational Behavioral literature has emphasized the importance of professionalism, which involves technical competency, maintaining high ethical standards, team member skills, executing plans developed by leaders, and the need to demonstrate leadership. Professionalism is the primary element of followership. After examining professional programs, both graduate and undergraduate, we offer the following as important professional skills for followership.

\section{Technical Competency}

Having technical skills and being able to adapt to changing work designs is imperative during a crisis. Whether it be computer, accounting, operative, the ability to learn new skills, procedures, and methods are necessary in a crisis situation. Work designs, such as job enlargement and job enrichment, have become increasingly utilized in the new work environment. Competency is essential to being a successful follower and contributor to organizational and departmental effectiveness. These skills will be necessary for the Millennial Generation, as they place a high value on teamwork, personal productivity, and fulfilling work (Meister \& Willyerd, 2010). 


\section{FIGURE 1 \\ A HIERARCHY OF FOLLOWERSHIP SKILLS}

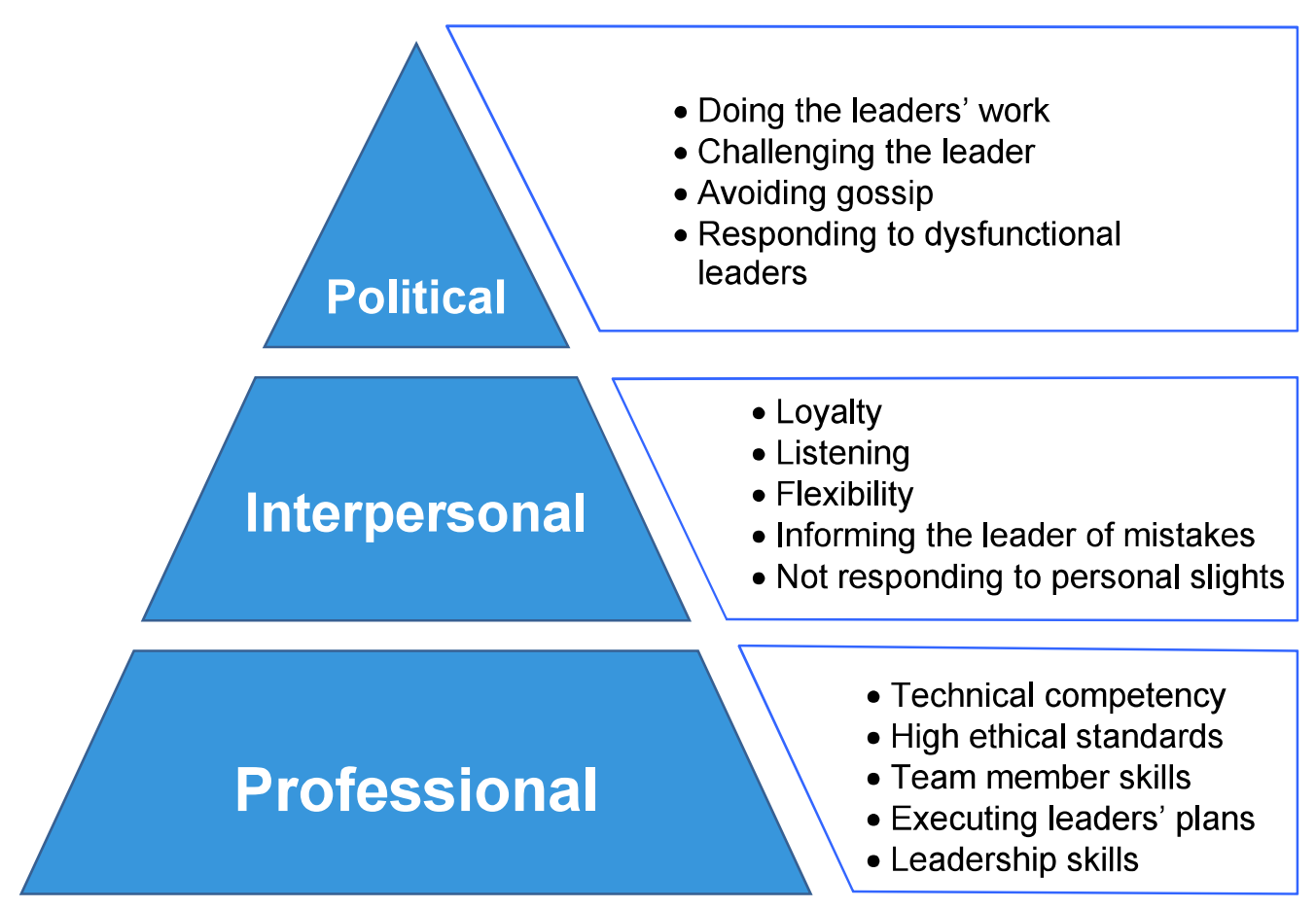

\section{High Ethical Standards}

Even in a crisis mode, there is no substitute for maintaining and practicing high ethical standards. Effective leaders expect and demand high ethical standards from followers. Failure to demonstrate high ethical standards will ensure little opportunity for leadership, compromise quality work, and shorten a career. Moreover, Generation $\mathrm{Y}$ workers perceive the honesty and integrity of their supervisors to be relevant (McDonald, 2016).

\section{Team Member Skills}

Being a productive team member is even more important in the current environment as workers adapt to new duties and responsibilities and may work remotely. For example, nurses function as part of a team with consensus-building skills and are expected to serve in various roles. In addition to teaching technical competency, nursing programs strongly emphasize team-building skills in an effort to enhance quality medical care. These skills are even more important for Gen Y and Gen Z in other professions. Likewise, these skills are necessary for Millennials, who enjoy strong peer relationships and may prefer a collaborative approach to teamwork more than previous generations (Hendricks \& Cope, 2013).

\section{Executing Leaders' Plans}

Since strategic plans may be developed at all levels within the organization, it is necessary for followers to embrace and help implement them. Even in smaller organizations, the CEO often develops the strategic plans and, therefore, expects followers to embrace a new direction and implement them successfully in their roles as followers (Whitlock, 2016).

\section{Leadership Skills}

As workers demonstrate effective followership skills, leadership opportunities may develop. As one assumes the role of a team or project leader, it remains important to develop followership skills. Since followership is the flip side of leadership, career success often involves utilizing both skill sets to advance 
within the organization. Failure to do so may truncate an individual's career, thus causing quality to be suboptimal (Bushardt, Young, \& Bari, 2018).

\section{Interpersonal Skills}

While technical competency is necessary for successful followership, interpersonal skills are an essential component of the paradigm. Interpersonal skills include loyalty, listening, adjusting to the leader's strengths and weaknesses, and informing the leader of mistakes. The ability to not respond to personal slights should also contribute to successful followership and enhance one's career for future advancement opportunities. Challenges may exist in applying these skills in a crisis mode with significant changes, such as a remote work environment. As the leader institutes these changes, interpersonal skills will be even more critical. While the list of interpersonal skills could be expanded, the following fundamental interpersonal skills are important.

\section{Loyalty}

Most leaders value loyalty among the followers and seldom forgive disloyalty. While supporting the leader, commitment does not involve compromising one's values. For example, unethical behavior is never a part of successful followership (Bushardt, Young, \& Bari, 2018). If the leader expects such behavior as part of followership, perhaps a job change or transfer is needed.

\section{Listening}

Followership requires the use of active listening skills since it is not enough only to hear. This skill may often be a challenge due to time management and other considerations, but a sincere effort should be made to support leaders in implementing directives. The issue is not whether one agrees with the leader but to sincerely attempt to understand what they are trying to communicate.

\section{Flexibility}

Given that leaders have both strengths and weaknesses, competent followers learn how to deal effectively with potential shortcomings. According to Relationship Awareness Theory, followership involves valuing the leaders' strengths while often moderating or overlooking their limitations (Porter, 1971). Strong followers help the leader overcome weaknesses by filling in the gaps of those weaknesses (Bushardt, Glasscoff, \& Doty, 2010)

\section{Informing the Leader of Mistakes}

Mistakes are part of the organizational context in that individuals may have inadequate information or make hasty decisions. Belludi (2018) advises, "Never let your boss be surprised by bad news." When mistakes happen in the organization, effective followers should go immediately to the leader and let him/her know, as few like to be surprised. If the follower made the mistake, he/she should take responsibility for the error. In addition, good leaders have the experience to offer suggestions to overcome or to best manage the mistakes. Leaders become more trusting and supportive of followers once they realize they have their confidence and trust.

\section{Not Responding to Personal Slights}

Followership requires individuals to not overreact to personal slights one perceives from their leader or contemporaries since organizational life is a "rough and tumble environment." A tough skin, coupled with a focus on competency, is normally the best approach. Leaders may be juggling many complex organizational problems and thus may be considered insensitive at times. Therefore, it is important to "let it go" to be a successful follower. Most leaders do not want to devote their time to what they perceive as petty issues among followers. Undermining behaviors may be disruptive, but good followers should develop the skills of managing-up (Raso, 2017). 


\section{Political Skills}

While professionalism is the foundation of followership, interpersonal skills build upon competency where political skills are the final element of successful followership. The term politics often has a negative connotation in organizations, but the complex nature of organizational life is that politics is pervasive. When people often say, "I do not play politics," the reality is that everyone plays politics; the only question is, does one do this poorly or effectively? When used in a Machiavellian manner, politics may have adverse effects on organizational effectiveness and, therefore, be destructive to one's career. Followership requires using political skills effectively, which may mean doing the leader's work, challenging the leader, avoiding gossip, and responding to dysfunctional leaders.

\section{Doing the Leader's Work}

Followership often involves performing some of the leader's work, even without receiving praise or rewards. In a crisis mode, leadership demands may be overwhelming with tremendous challenges, time pressures, and new procedures. Followers can step in to ease the burden by handling many of the issues. Once the work is completed, credit often goes to the leader and not the follower who made it happen. Effective followers understand the supportive role and thus perceive that contributions will be rewarded later in the form of promotions, pay increases, and other desirable outcomes.

\section{Challenging the Leader}

Even though leaders may present a bad idea to enhance organizational effectiveness, good followership involves listening to explanations and reasoning. Successful followers avoid challenging the leader publicly, as it undermines his/her authority and is likely to lead to defensive behavior. Naturally, poor ideas should be challenged; however, a private meeting where the subordinate shares a candid response is appropriate and likely to be valued by the leader. While followership requires a candid conversation to express one's views, the final decision is ultimately up to the leader. Successful followers may often guide the leader, in private, away from flawed ideas whenever possible. When the leader insists on implementing what is perceived by the follower as a poor decision, efforts to successfully implement such a decision may be appropriate. Effective implementation may often offset a poor decision by the leader and ultimately become successful when operationalized.

\section{Avoiding Gossip}

Effective followership involves avoiding gossip, which may undermine the leader's position power. Since organizations are political institutions, members often compete for positions of power. However, when working closely with the leader, their limitations are usually obvious. Being a good follower involves emphasizing the leaders' strengths and not gossiping with others regarding their weaknesses. Finally, many unknows exist in times of crisis, and employees may "second guess" with an active grapevine.

Although it is not uncommon for organizational members to plot to overthrow the leader, followership involves not engaging in these political attacks. According to Machiavelli (2006), "... subjects cannot undertake more perilous and foolhardy enterprises than conspiracies, which are in every respect more difficult and dangerous; and thence it is that, although so often attempted, yet they so rarely attain the desired object."

\section{Responding to Dysfunctional Leaders}

Although leaders possess strengths and weaknesses due to human nature, many times, weaknesses are their strengths that have been taken to excess (Porter, 1971). The central focus of followership is helping the leader realize important strengths while helping to overcome the weaknesses to facilitate organizational effectiveness. The reality of organizational life is that dysfunctional leaders are often placed in positions of power while their flaws are of such a nature that followership is limited. Dysfunctional leaders may be ethically impaired, dishonest, vindictive, or mean-spirited. In these cases, followers have limited options in their roles as followers. 
Our experience is that if the leader is genuinely dysfunctional, it is only a matter of time before he/she is removed from the position. If followers changed jobs every time there is a dysfunctional leader, the result could be damaging to their careers (Bushardt \& Brooking, 1982). When faced with a dysfunctional leader, one can utilize the old Japanese proverb, "The nail that sticks out gets hammered down." Therefore, the follower should continue with professionalism but keep one's distance and opinions about the dysfunctional leader to oneself.

There are times when one has a dysfunctional leader demanding a compromise counter to the subordinate's professional standard, thus creating an untenable position. Therefore, changing jobs is the primary recourse since lowering professional standards by engaging in unethical behavior compromises organizational effectiveness and damages the career. If this is the only true course of action, followers should consider a job search while still employed and then leave quietly.

\section{TIME PROGRESSION AND LEADERSHIP LEARNING SKILLS}

Figure 2 shows stages of development as followers learn skills and progress to become leaders. Since the three followership skills are the foundation for developing effective organizational leaders, we observed their growth and development in four stages. These include from entry into an organization as an apprentice until the time they became leaders. The following four stages over time are offered: (1) Apprentice/Novice (2) Team Player, (3) Decision Maker, and (4) Leader/Manager. At each developmental stage, competency is not only expected but required.

Individuals begin their professional career as a Novice/Apprentice, learning from other professionals in their area. The Novice/Apprentice should focus on learning practices and organizational policies and procedures, both formal and informal. The apprentice develops professional followership skills through technical competence, ethical standards, and executing the leader's plans. Next, effective followers embrace new opportunities as a time to grow and develop interpersonal followership skills as a team player. After developing interpersonal skills, more responsibilities and decision making may be offered.

\section{FIGURE 2}

\section{TIME PROGRESSION AND LEARNING FOLLOWERSHIP SKILLS}

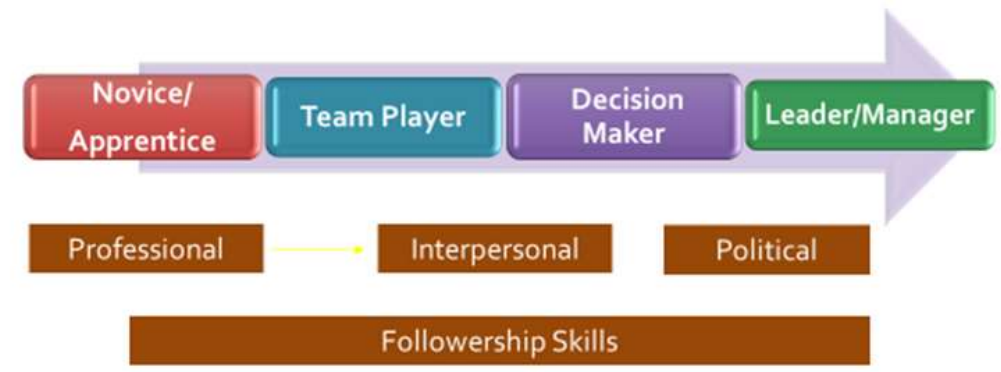

Finally, individuals learn political skills as they progress to a leader/manager role. The pinnacle leadership position will be achieved once proficiency in all three levels of followership skills are demonstrated and will be important to the leader's ultimate success. 


\section{DISCUSSION}

Using past studies and organizational leadership experiences, we examine the importance of followership in the new environment. A major challenge for Gen Y and Gen $\mathrm{Z}$ in a crisis management situation will be becoming a valuable part of the team. Further, it is imperative to guide and direct these generations with the identification of important followership skills. In order to enhance one's career, understanding and becoming knowledgeable in followership skills are necessary. We identified three types of followership skills placed in a hierarchy. Our model illustrates how followers move through these stages while learning the three skills, professional, interpersonal, and political, to enhance their ability to grow as professionals. Further, we identified the following progression as they master these skills and progress to an effective leadership position: (1) Novice/Apprentice who begins to learn professional skills, (2) Team Player, who has become a competent professional; (3) Decision Maker demonstrating proficiency in both professional and interpersonal skills; and ultimately, (3) Leader/Manager with a mastery of followership skills with an emphasis on political skills. Followership skills are important in every role, although navigating the complex nature of organizational politics is typically mastered at higher management levels.

A major challenge for managers will be coordinating and directing multiple generations with different values. Practitioners should recognize that different generations may be valuable assets to the organization and eventually be very influential in organizational decision making. Organizations should be aware of these generations as talented resources vital to organizational success and, therefore, work to enhance the development of both Gen Y and Gen Z and to foster an environment in which different generations may be effective as followers.

\section{REFERENCES}

Balludi, N. (2018). No boss likes a surprise--good or bad. Right attitudes: Ideas for impact. Retrieved from www.rightattitudes.com/2018/01/16never-suprise-the-boss/.

Batcheller, J. (2012). Learning how to dance: Courageous followership: A CNO case study. Nurse Leader, 10(2), 22-24.

Bushardt, S.C., \& Brooking, S. (1982). Managing the boss: Learning to manage your superior and reap recognition and reward. Management World, 11(5), 38-39.

Bushardt, S.C., Glascoff, D.W., \& Doty, D.H. (2010). Career advancement strategies for the new decade: Out with the old; in with the new. Journal of Business and Training Education, 19, 29-34.

Bushardt, S.C., Young, M., \& Bari, A. (2018). Transitioning to management: Challenges and opportunities for the millennial generation. Journal of Business Diversity, 18(1), 9-16.

Hendricks, J.M., \& Cope, V.C. (2013). Generational diversity: What nurse managers need to know. Journal of Advanced Nursing, 69(3), 717-725.

Machiavelli, N. (2006). The Prince, translated by W. K. Marriott. Gutenberg ebook of the Prince.

Malakyan, P.G. (2014). Followership in leadership studies: A case of leader-follower trade approach. Journal of Leadership Studies, 7(4), 6-22.

McDonald, P. (2016). Tips for hiring, managing, and retaining Gen Z workers. CPA Practice Advisor, 26(2), 5.

Meister, J., \& Willyerd, K. (2010). Mentoring Millennials. Harvard Business Review, 88(5), 68-72.

Phillips, A.V. (2017). Inspiring followership. Nursing Management, 48(12), 12-13.

Porter, E.H. (1971). Strength Deployment Inventory. Pacific Palisades, CA: Personal Strengths Assessment Service.

Raso, R. (2017). In favor of followership. Nursing Management, 48(10), 6.

Whitlock, J. (2013). The value of active followership. Nursing Management, 20(2), 20-23. 